\title{
Multiaxial Fatigue Life Calculation Model for Engineering Components in Rolling-Sliding Contact
}

\author{
Robert Basan ${ }^{1, *}$, Tea Marohnić ${ }^{1}$ \\ ${ }^{1}$ Faculty of Engineering, University of Rijeka, Vukovarska 58, HR-51000 Rijeka, Croatia
}

\begin{abstract}
Number of important engineering components and elements such as gears, rollers, bearings operate in conditions of rolling-sliding contact loading. Determination of fatigue lives of such components and elements is very important for engineering practice but remains quite chalenging task due to complex states of stress and strain in the material in the vicinity of contact (multiaxiality, non-proportionality, rotation of principal axes, mean compressive stress) as well as complex contact conditions such as loading amplitude, complex geometry of bodies in contact, type of lubrication, value of coefficient of friction, etc. Proposed fatigue life calculation model for cases of rolling-sliding contact is based on critical plane approach in the form of Fatemi-Socie crack initiation criterion. Developed model was implemented in the case of gears teeth flanks in mesh and compared with results and fatigue lives of gears reported in literature. Good agreement was determined confirming validity of developed model. Further advantage of presented approach and developed model is obtained information on critical location(s) and critical plane(s) orientation which can subsequently be used for estimation of crack shapes in initial phases of their growth and later damage type into which they can be expected to develop.
\end{abstract}

\section{Introduction}

Rolling-sliding contact loading and fatigue, remain significant problems and relevant research topics since a number of important components and elements such as gears, rollers, bearings operate in these conditions. These components are highly loaded and due to cyclic transmission of motion and loading/power are prone to damage caused by material fatigue, especially in the surface layer close to the area of contact. With some exceptions, in majority of cases, such fatigue damage is progressive and usually leads to the failure of the component. Depending on different factors, this fatigue damage can manifest itself in a number of different forms. [1,2]

Determination of fatigue life of these components is still quite a chalenging task since this particular type of loading causes complex states of stress and strain in the material in the vicinity of area of contact featuring multiaxiality, non-proportionality, rotation of

*Corresponding author: robert.basan@ riteh.hr 
principal axes during the contact and presence of mean compressive stress. Main factor that additionaly contributes to the complexity is variable and difficult to determine loading cycle which is further influenced by significant number of conditions and parameters such as variable loading amplitude, complex geometry of bodies in contact, type of lubrication and value of coefficient of friction. In order to extend their durability and fatigue life, further highly variable factors such as material properties and their variability due to different heat and surface treatments need to be taken into account. [1, 3, 4, 5]

\section{Existing approaches and calculation models}

One of the main chalenges for determination of load capacity and fatigue lives and consequently aleviation or avoidance of fatigue damage of components and elements operating in rolling-sliding contact conditions, is precise and correct characterization and calculations of stresses and strains and their evolutions during cycle(s) of rolling-sliding contact loading and properly taking into account numerous external and internal influences that affect it. For these purposes different analytical, semi-analytical and numerical approaches and models have been proposed in literature. Early research such as [6-8] significantly based on empirical data and analytical calculation procedures, atempt to take into account various influences in order to offer procedures and guidelines usable for preventing various modes of fatigue damage of differently surface-hardened based gear teeth flanks. In [9] equivalent Von Mises stress is proposed as a relevant parameter whose maximum value needs to be within hardened layer with higher yield stress in order to prevent development of fatigue damage i.e. pitting. Contact conditions and stresses/strains were calculated using equivalent model of two contacting cyclinders which was implemented in FE software. Stress-based approach is used in [10] where durability of large rolling bearings was researched. In [11] rolling-sliding contact of cylindrical bodies was investigated using more advanced ELKHP material model and relation was found between depth of damage appearance and depth of plastification. In [12], Hertter takes into account multiaxial and non-proportional nature of stress state on gear teeth flanks durngthe mesh and proposes calculational procedure based on modified shear stress intensity theory (ger. Schubspannungsintensitaetshypothese - SIH). For calculation of stresses/strains, detailed analytical/numerical procedure was used in which gear tooth was represented with 2D model loaded with corresponding distributed loading. In [3] authors have implemented strain-based approach for determination of fatigue lives and contact model used was similar to that used in [9].

\section{Proposed calculation model}

Overview of main, general steps of proposed procedure is given on diagram in Figure 1. Individual steps need to be defined separately as they may differ significantly depending on the details of the contact problem in question. Apart from that, the procedure may be divided in two steps - development of loading model needed for definition of the contact problem and calculation of stresses/strains and their evolutions during loading cycles and fatigue calculation model and postprocessing of obtained results. For these substeps, different approaches and techniques may be implemented. In following text, developed calculation model for cyclindrical involute gear teeth flanks - a representative case of rolling-sliding contact loading is presented in more detail. 


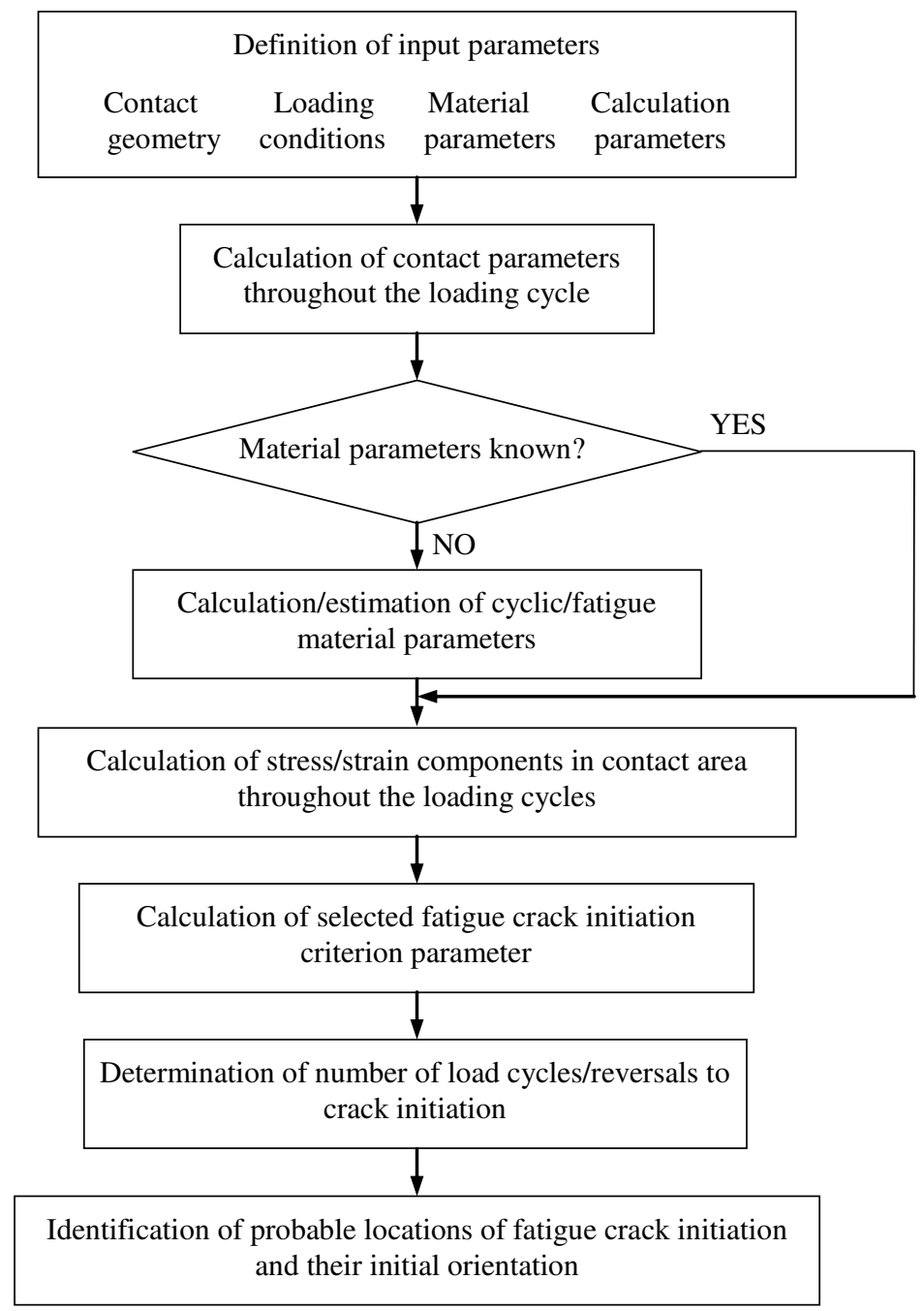

Fig. 1. Overview of the complete proposed calculation procedure

\section{Application on gear teeth flanks in contact during the mesh}

\subsection{Loading model}

During operation, flanks of involute spur gear teeth are submitted to relative motion comprising of simultaneous rolling and, to the variable degree, sliding. Since aside from movement, power is also transmitted during the mesh, flanks in contact are mutually pressed by normal force and due to the friction, they are also affected by corresponding tangential forces and experience high cyclic contact pressures. [2, 13, 14].

Mentioned loading causes very complex stress state in the material of the tooth flank in the vicinity of the contact. Its main features are: multiaxiality, non-proportionality, rotation of principal axes and presence of mean compressive stress. Stresses and stress state in the contact region are additionally affected by changing geometry of bodies in contact, type of lubrication, value of coefficient of friction and residual stresses. Figure 2 shows in 
somewhat simplified manner how these factors affect the value and distribution of contact pressure and equivalent stresses at gears flanks during the mesh $[4,5,15]$.
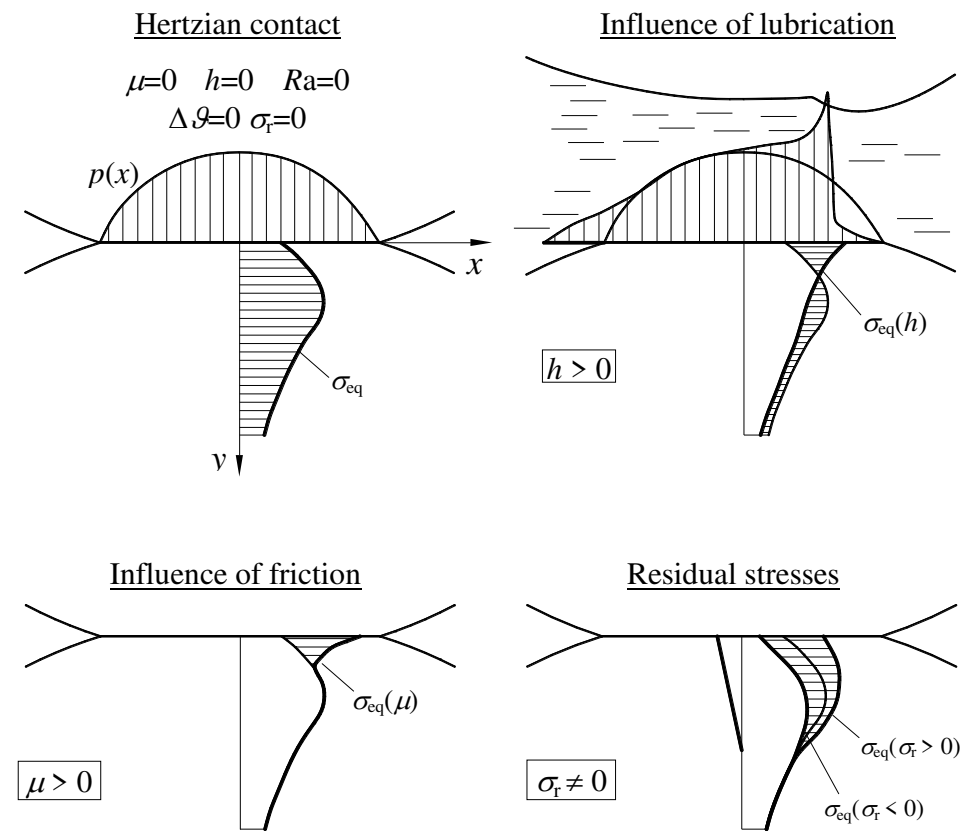

$\underline{\text { Surface roughness }}$

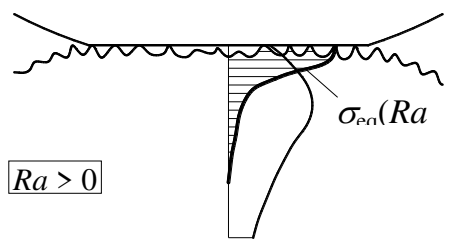

Influence of heat

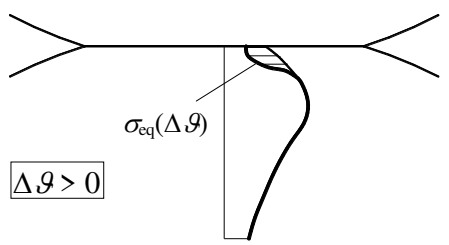

Fig. 2. A simplified representation of the influences that contact conditions have on the equivalent stress in material of gear teeth flanks during the mesh

Due to it's versatility finite element analysis is usually used for purpose of analyzing and performing above mentioned calculations of stresses and strains and their evolutions during loading cycles (and for determination of fatigue lives). However, substantial amount of time and effort is still required for modelling of geometry and mentioned influences so that if larger number of cases needs to be evaluated, this approach quickly becomes prohibitive.

For this representative case of rolling-sliding contact loading, calculation of values and evolution of stress/strain components at and under teeth flanks' surfaces was done using developed semi-analytical calculation model of gear teeth in contact $[5,16]$. It is based on well-known equivalent model where flanks in contact are replaced with cylinders of appropriate radii $[17,18]$ (Figure 3 ) and where contact loading i.e. normal and tangential forces acting on flank surface during the mesh are approximated with distributed normal and tangential loading $p(x)$ and $q(x)$ (Figure 4), both of which can be modified to properly acount for influences presented in Figure 3. 

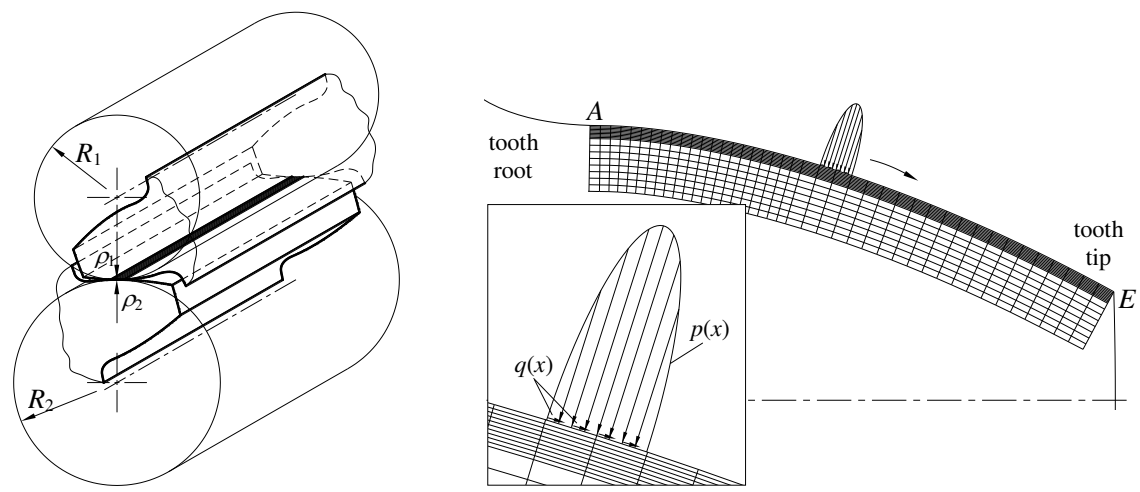

Fig. 3. Equivalent model of meshed gear teeth flanks and loading on discretized tooth flank $[5,16]$

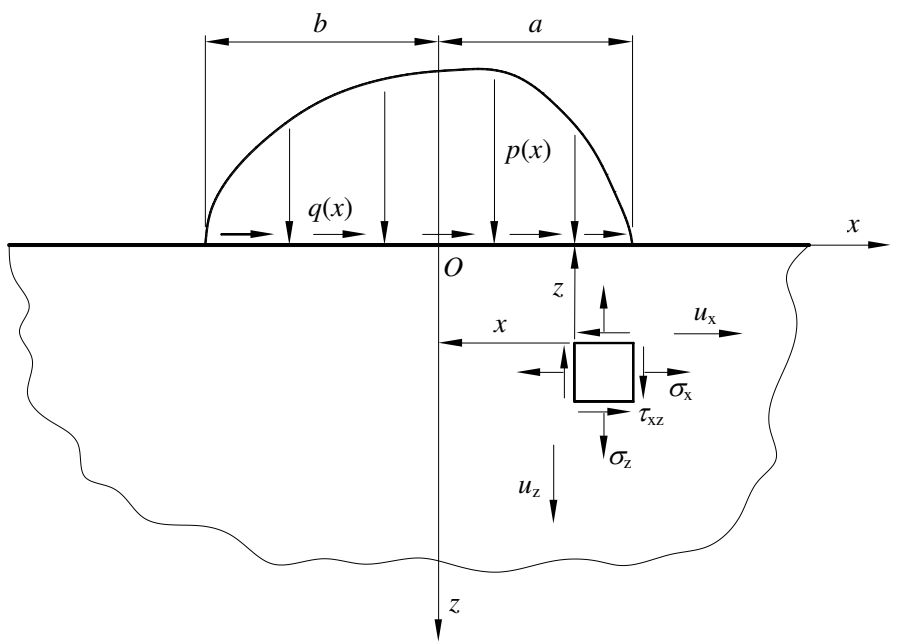

Fig. 4. 2D representation of an elastic half-space with distributed loading on boundary plane

One notable advantage of this approach is that enables efficient and sufficiently accurate modelling of different lubrication conditions - dry, mixed-mode lubrication as well as EHD lubrication conditions characterized by by a local pressure extreme in the outer part of the contact area that occurs due to a local reduction in oil film thickness caused by the elastic deformation of the bodies in contact $[5,16]$

\subsection{Fatigue life model}

For the purpose of determination of fatigue lives i.e. number of load reversals until crack initiation of components and elements operating in rolling-sliding contact conditions, different model and criteria have been proposed in literature. Here, critical plane based approach in the form of Fatemi-Socie crack initiation criterion [19] was selected (1).

$$
F P_{\mathrm{FS}}=\frac{\Delta\left(\frac{\gamma_{\max }}{2}\right)}{2}\left(1+k \frac{\sigma_{\mathrm{n}}^{\max }}{R_{\mathrm{e}}}\right)=\frac{\tau_{\mathrm{f}}^{\prime}}{G}\left(2 N_{\mathrm{f}}\right)^{b_{0}}+\gamma_{\mathrm{f}}^{\prime}\left(2 N_{\mathrm{f}}\right)^{c_{0}}
$$


Calculation procedure is performed in series of steps for every point of tooth flank and for every load step within single load cycle. Overview is provided in diagram on Figure 5.

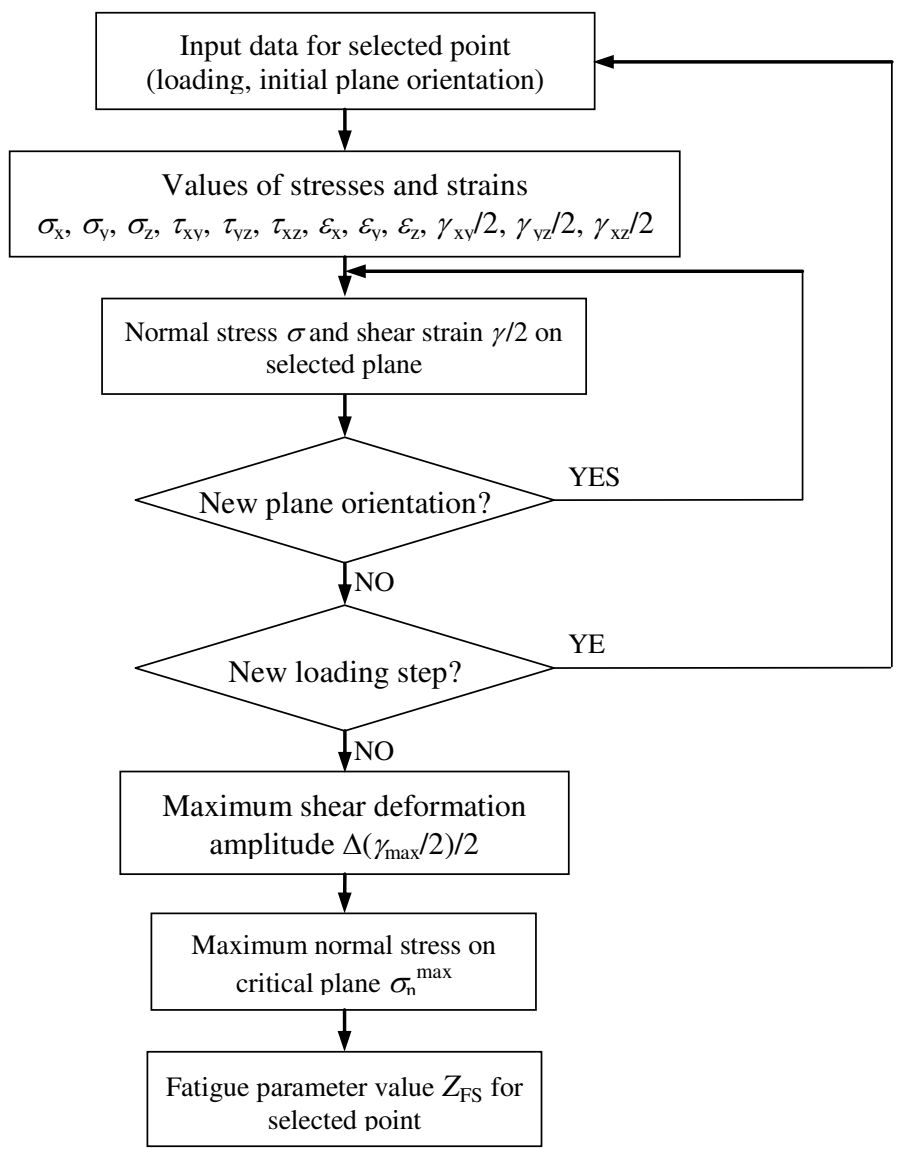

Fig. 5. Procedure for determination of critical plane crack initiation criterion fatigue parameter

Maximum shear strain amplitude $\Delta\left(\gamma_{\max } / 2\right) / 2$ is iteratively calculated on series of differently oriented planes. Since flanks contact is considered as $2 \mathrm{D}$ problem instead of $3 \mathrm{D}$, critical plane is searched for only among those defined by value of angle $\theta=45^{\circ}$ and $\theta=90^{\circ}$ while for each of these, angle $\varphi$ is varied from $0^{\circ}$ to $180^{\circ}$ in steps of $1^{\circ}$. Number of load reversals to crack initiation $2 N_{\mathrm{f}}$ is calculated using expression (2)

$$
Z_{\mathrm{FS}}=\frac{\tau_{\mathrm{f}}^{\prime}}{G}\left(2 N_{\mathrm{f}}\right)^{b_{0}}+\gamma_{\mathrm{f}}^{\prime}\left(2 N_{\mathrm{f}}\right)^{c_{0}} .
$$

\section{Results}

Discussed model was implemented on the case of gears teeth flank in contact and compared with results and fatigue lives of gears made of low-alloy steel $42 \mathrm{CrMo} 4$ reported in literature for which good agreement was determined confirming validity of developed 
model. More detailed results and comparisons of obtained fatigue lives of investigated gearing was presented in [5].

In addition to fatigue lives, developed calculation model captures other important influences such as different orientation of pitting damage due to influence of sliding direction. If the damage is below the kinematic diameter, the tip of the triangular pit is generally directed towards the root of the tooth, and if the damage is above the kinematic diameter, the tip of the triangle is directed towards its tip which is consistent with results presented in Figure 6.
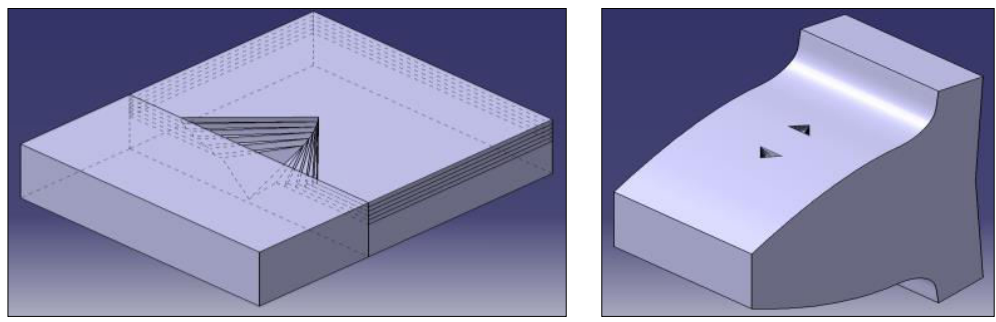

Fig. 6. Morphology and orientation of fatigue damage correctly determined through the calculation model results

Figures 7 and 8 show comparison of the morphological details of individual pits on gears flanks as determined in experimental study in [20] and as determined based on results of developed calculation model. From this good agreement it can be further concluded that the initiation of pitting cracks on the gear tooth flank and their development, at least in the earliest stages of their growth, are largely dominated by cyclic shear deformations since they are the basic influential parameter in the used crack initiaon criterion used in the developed mathematical model.
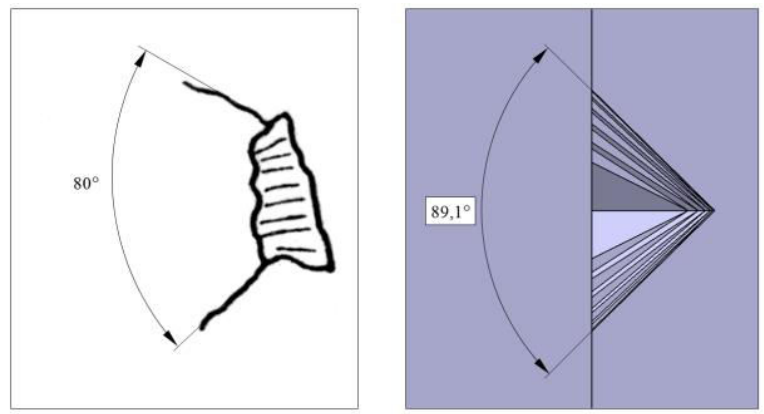

Fig. 7. A simplified representation of the influences that contact conditions have on the equivalent stress in material of gear teeth flanks during the mesh
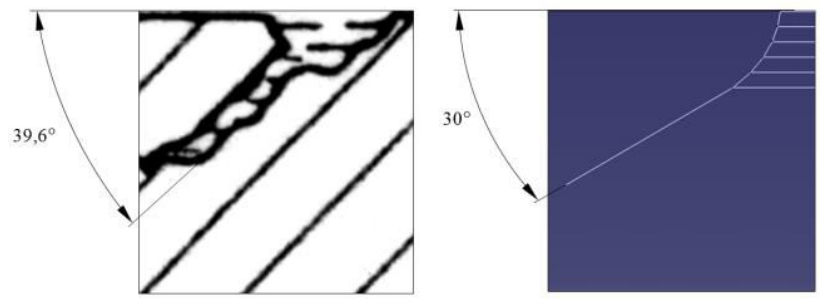

Fig. 8. A simplified representation of the influences that contact conditions have on the equivalent stress in material of gear teeth flanks during the mesh 


\section{Conclusion}

Developed calculation model enables taking into account of different loading conditions during the mesh of involute spur gears' teeth flanks as well as other influencing factors. Further advantage of the presented approach and developed model is the fact that in addition to the detailed information on fatigue lives of loaded areas, information on critical location(s) and critical plane(s) orientation is also obtained - very useful information which can subsequently be used for estimation of crack shapes in initial phases of their growth and later damage type into which they can be expected to develop. In future research, dveloped model will be used to investigate the influence of different loading conditions and other relevant factors such as material and heat treatment on durability of gear teeth flanks.

This work has been supported by the University of Rijeka under the project number [13.09.1.2.09]. The support is gratefully acknowledged.

\section{References}

1. B. Aberšek, J. Flašker, How gears break (Witpress, Southampton, Boston, 2004)

2. R. Basan, M. Franulović, M. Lengauer, B. Križan, Eng rev 30, 2, 37-46 (2010)

3. M. Šraml, J. Flašker, I. Potrč, International Journal of Fatigue, 25, 585-595, 2003.

4. S. Glodež, Model utrujanja zobnih bokov s upoštevanjem parametrov lomne mehanike (Fakulteta za strojništvo, Univerza v Mariboru, Maribor, 1996)

5. R. Basan, Fatigue and damage of the gear tooth flank (Faculty of Engineering, University of Rijeka, Rijeka, 2009)

6. R. Pederson, S.L. Rice, Case crushing of carb. and hard. gears., Trans. SAE (1961)

7. R. Wolkenstein, Antriebstechnik 13, 579-585, 637-641, 691-700 (1974)

8. E. Sandberg, A Calculation method for subsurface fatigue (ISGPT, Tokyo, 1981)

9. S. Glodež, J. Flašker, Z. Ren, S. Pehan, Optimisation of hardened layer thickness on gears (Design 96, Opatija, 1996)

10. O. Zwirlein, W.P. Wieland, Case depth for ind hard slewing bearing..., SAE (1983)

11. A.M. Kumar, Analysis of sub-surface crack initiation under rolling contact (Vanderbilt University, Nashville, 1989)

12. T. Hertter, Rechnerischer Festigkeitsnachweis der Ermüdungstragfähigkeit vergüteter und einsatzgehärteter Stirnräder (TU München, München 2003)

13. A.V. Olver, J. Eng Trib. 219, 313-330 (2005).

14. W.A. Glaeser, S.J. Shaffer, Contact fatigue - ASM Handbook, Vol. 19, Fatigue and Fracture (ASM International, 1996)

15. P. Fritsch, Oberflächenfeingestalt einsatzgehärteter Zahnräder - Einfluß auf Bauteilbeanspruchung,... (TH Aachen, Aachen, 1991)

16. R. Basan, M. Franulović, Evolution of Stress Components at Involute Gears Teeth Flanks During the Mesh (Int Conf Power Transmissions 2009, Thessaloniki, 2009)

17. K.L. Johnson, Contact mechanics (Cambridge University Press, Cambridge, 1985)

18. S. Glodež, Z. Ren, Th App Frac Mech 30, 159-173 (1998)

19. A. Fatemi, D.F. Socie, Fatigue Fract Engng Mater Struct. 11, 149-165 (1988)

20. G. Niemann, H. Bötsch, Konstruktion, 12, (1966) 